\title{
New Approaches to the Treatment of Age- Related Brain Disorders
}

\author{
M. Da Prada
}

\begin{abstract}
Two novel reversible enzyme inhibitors involved in monoamine metabolism are described. The novel and reversible inhibitors are the catechol-O-methyl-transferase (COMT) inhibitor, Ro 40-7592 (3,4-dihydroxy-4'methyl-5-nitrobenzophenone), and the monoamine oxidase type-B (MAO-B) inhibitor, Ro 19-6327 (N-(2-aminoethyl)5-chloro-2-pyridine carboxamide $\mathrm{HCl}$ ). These may be of special therapeutic benefit in Parkinson's and Alzheimer's diseases.
\end{abstract}

RÉSUMÉ: Nouvelles approches du traitement des affections du cerveau reliées au vieillissement. Nous décrivons deux nouveaux inhibiteurs enzymatiques à action réversible impliqués dans le métabolisme monoaminergique. Ces nouveaux inhibiteurs dont l'action est réversible, sont des inhibiteurs de la catéchol-O-méthyl-transférase (COMT), le Ro 40-7592 (3,4-dihydroxy-4'-méthyl-5-nitrobenzophénone) et l'inhibiteur de la monoamine oxydase de type-B (MAO-B), Ro 19-6327 (N-(2-amino-éthyl)-5-chloro-2-pyridine carboxamide HCI). Ces produits pourraient s'avérer particulièrement bénéfiques dans le traitement de la maladie de Parkinson et de la maladie d'Alzheimer.

Can. J. Neurol.Sci. 1991; 18:384-386

This survey deals with the main neurochemical characteristics of two novel reversible enzyme inhibitors involved in monoamine metabolism and the rationale for their therapeutic use in age-related neurodegenerative brain disorders, in particular Parkinson's disease (PD) and Alzheimer's disease (AD). The novel and reversible inhibitors are the catechol-O-methyl-transferase (COMT) inhibitor, Ro 40-7592 (3,4-dihydroxy-4'methyl-5-nitrobenzophenone, and the monoamine oxidase typeB (MAO-B) inhibitor, Ro 19-6327 (N-(2-aminoethyl)-5-chloro2-pyrdine carboxamide $\mathrm{HCl}$ ).
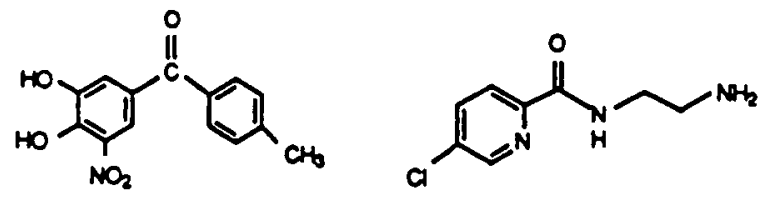

Chemical structure of Ro 40-7592 (left) and Ro 19-6327 (right)

\section{Novel Strategies for the Treatment of Parkinson's Disease}

For the symptomatic treatment of PD coadministration of the COMT inhibitor Ro 40-7592 with Madopar ${ }^{\circledR}$ is proposed to optimize the neurotransmitter replacement therapy with 3,4dihydroxy-phenyl-L-alanine (DOPA). The potent COMT inhibitor Ro 40-7592, by blocking the COMT activity intra-and extra-cerebrally should markedly improve the pharmacokinetics and pharmacodynamics of DOPA. Recent trials in healthy subjects provided a first clear evidence that Ro 40-7592 (200 mg) given in combination with Madopar ${ }^{\mathbb{B}}-125$ standard markedly enhances the bioavailability of DOPA in plasma. These new findings also allow us to anticipate that the pharmacokinetics of DOPA will be further optimized with a treatment which combined Ro 40-7592 with the controlled release formulation Madopar $^{(8)}$ HBS. ${ }^{1}$

Alternatively, the highly selective MAO-B inhibitor Ro 196327 given with Madopar ${ }^{\circledR}$ might be useful in the therapy of PD because Ro 19-6327, like the irreversible MAO-B inhibitor selegiline (l-deprenyl), should improve dopamine (DA) neurotransmission by blocking the beakdown of DA in the nigrostriatal dopaminergic nerve terminals 2,3 or adjacent cells. Recently it was suggested that exogenous neurotoxins could play a critical role in the process of neuronal degeneration that characterizes PD. For instance, inhibition of MAO-B with selegiline 4 or Ro 19-63275 dramatically reduces the conversion of 1-methyl-4phenyl-1, 2, 3, 6-tetrahydropyridine (MPTP) into its dopaminergic neuroxtoxin 1-methyl-4-phenylpyridinium ion (MPP+). The discovery that a relatively simple compound, such as MPTP, produces Parkinson-like features in humans and animals and the fact that MAO-B inhibitors counteract MPTP-induced neurotoxicity in experimental animals raised the suspicion that environmental toxins might cause PD. ${ }^{6}$ Most important, several clinical studies indicate that the MAO-B inhibitor selegiline might protect against neurcucgenerative diseases of the aging brain, e.g. in

From the Pharma Research Department, F. Hoffmann-La Roche Ltd., Basel, Switzerland

Reprint requests to: M. Da Prada, Pharma Research Department, F. Hoffmann-La Roche Ltd., Ch-4002 Basel, Switzerland 
$\mathrm{PD}^{7,8}$ and in $\mathrm{AD} \cdot{ }^{9,10}$ It has also been postulated that the oxidative determination of DA by MAO-B with production of hydrogen peroxide, in the human brain, could be deleterious for the nigrostriatal dopaminergic neurones. Thus, due to the abnormally low content of reduced glutathione and/or in the increased amount of ferrous iron in the substantial nigra of Parkinsonian patients, the hydrogen peroxide formed by deamination of DA might lead to the generation of oxygen free radicals which in turn produce lipid peroxidation, neuronal membrane damage and cell death. ${ }^{11,12}$ In Parkinsonian patients treated with Madopar ${ }^{(\mathbb{B}}$ or Sinemet ${ }^{\circledR}$ MAO-B inhibitors might decrease the risk of hydroxyl free-radical formation by reducing the formation of hydrogen peroxide generated from the oxidation of DA. According to the free-radical as well as to the neurotoxin hypothesis the MAO-B enzyme might play a pivotal role in the physiopathological processes underlying the so-called "degenerative" diseases of the aging brain.

\section{From Madopar ${ }^{\circledR}$ Standard to Madopar ${ }^{\circledR}$ HBS and the Rationale to Combine MadoparR with the COMT Inhibitor Ro 40-7592}

DOPA, the precursor amino acid of the catecholamine (CA) neurotransmitters including DA, administered in combination with peripheral DOPA decarboxylase (DDC) inhibitors, e.g. benserazide (Madopar $\left.{ }^{(}\right)$or carbidopa (Simemet ${ }^{\circledR}$ ), is still considered the major therapeutic agent for the treatment of PD.13,14 The majority of the problems encountered in the therapy with DOPA originate from its complex pharmacokinetics and pharmacodynamics. ${ }^{15}$ Being an amino acid, DOPA follows multiple metabolic pathways, and in the gastrointestinal tract as well as at the blood-brain barrier it competes with the transport of a number of large neutral amino acids. Competition for the bloodbrain barrier uptake occurs also between DOPA and its Omethylated derivative 3-O-methyl DOPA (3-OMD). 3-OMD is a poor substrate for DDC and because of a much longer half-life (about $15 \mathrm{~h}$ ) than DOPA (about $1 \mathrm{~h}$ ) accumulates in the plasma of patients treated with Madopar ${ }^{\circledR}$ and Sinemet ${ }^{\circledR}$. The ratio of mean plasma 3-OMD to DOPA concentrations can be as large as 14:1 and could lead to clinical deterioration of the patients. ${ }^{15}$ Elevated 3-OMD concentrations have sometimes been connected to dyskinesias or to on-off phenomena. To reduce the magnitude of fluctuations in plasma DOPA concentrations novel controlled-release formulations e.g. Madopar $^{\circledR} \mathrm{HBS}^{16}$ or Sinemet ${ }^{\circledR}$ CR4 ${ }^{15}$ have been recently introduced.

The controlled-release formulations of DOPA plus DDC inhibitors reduce the sudden formation of peak concentrations of DOPA in plasma reducing the number of daily "off" periods. The advantage of these formulations is to prolong the maintenance of therapeutic DOPA levels in plasma thereby increasing the mobility of the patients even during the night. ${ }^{17}$

\section{Neurochemical Characteristics of the COMT Inhibitor Ro 40-7592}

The nitrocatechol derivative Ro $40-7592$ is a competitive $(\mathrm{Ki}=30 \mathrm{nM})$ inhibitor of COMT, very active in vitro $\left(\mathrm{IC}_{50}\right.$ in rat liver $=36 \mathrm{nM})$ and in vivo $\left(\mathrm{ED}_{50}\right.$ for rat liver and kidney enzyme inhibition: 2.7 and $1.2 \mathrm{mg} / \mathrm{kg}$ p.o., $1 \mathrm{~h}$ ). Ex vivo, a reliable index to assess COMT inhibition in cerebral and extracerebral tissues uses the decreased formation of 3-OMD and homovanillic acid (HVA) in rat brain and plasma.' Several pre- clinical studies have shown that Ro 40-7592 administered p.o. in combination with benserazide and DOPA almost completely blocks the formation of 3-OMD in rat brain and plasma. 1.18 In these experiments, in addition, a long-lasting increase of DOPA was measured in plasma ${ }^{17}$ paralleled by a marked and prolonged increased in brain DA. ${ }^{1}$ In the same experimental condition, a marked decrease of the HVA content was measured in the brain with a parallel remarkable increased of 3,4-dihydroxphenyllacetic acid. ${ }^{1}$ Brain nonadrenaline and $\mathrm{H} 5$-hydroxytryptamine were unaffected.

In conclusion, by increasing the bioavailability and possibly prolonging the plasma half-life of DOPA as well as by reducing the formation of 3-OMD, Ro 40-7592, combined with peripheral DDC inhibitors and DOPA, e.g. in Madopar ${ }^{\circledR}$ standard or HBS is expected to markedly improve the therapy of PD patients.

In healthy subjects Ro 40-7592 at single oral doses was well tolerated up to $800 \mathrm{mg}$ and, at this dose, the compound markedly inhibited $(>80 \%)$ human erythrocyte COMT activity for at least $4 \mathrm{~h}$. As already observed in rat, the formation of 3-OMD was virtually suppressed also in human, when Madopar ${ }^{\circledR} 125$ was co-administered with Ro 40-7592 (200 mg), and DOPA bioavailability was doubled. The available clinical data support the notion that Ro 40-7592 combined with Madopar ${ }^{\circledR}$ standard, and even more so with Madopar ${ }^{\circledR}$-HBS, will significantly improve DOPA pharmacokinetics (maintaining for several hours optimal therapeutic concentrations of DOPA in plasma by avoiding the formation of sharp peak of DOPA) and prevent formation and accumulation of 3-OMD in plasma and brain. It is anticipated that, in the near future, the combination of controlled-release formulations of DOPA with Ro 40-7592 will represent an optimal therapeutic regimen by reducing the dose of DOPA and by prolonging interdose intervals.

\section{The Novel, Reversible Highly Selective MAO-B Inhibitor Ro 19.6327}

To date, selegiline is the only MAO-B inhibitor used clinically as adjunct to Madopar ${ }^{\circledR}$ or Sinemet ${ }^{\circledR}$ to improve symptom fluctuations in $\mathrm{PD}^{19}$ and as possible neuroprotective agent in $\mathrm{PD}^{7.8}$ and $\mathrm{AD}, 5,6$ However, selegiline at relatively low doses $(20 \mathrm{mg}$ daily) and under long-term therapy does not only inhibit MAO$\mathrm{B}$ but also, to some extent, inhibits MAO- $\mathrm{A}^{5}$ with risk of hypertensive crises (cheese-effect). Apart from its low specificity, the irreversible MAO-B inhibitor selegiline can be metabolized to potentially neurotoxic derivatives e.g. (-)methamphetamine and (-)amphetamine. ${ }^{20}$ In contrast to selegiline, Ro $19-6327$ belongs to a new chemical class of non-toxic, mechanism-based, fully reversible, and highly selective MAO-B inhibitors both in vitro and ex vivo. Ro 19-6327 is short-lasting, since enzyme activity returned to control values $48 \mathrm{~h}$ after dosing even when the compound is administered at high doses $(100 \pi \mathrm{mol}(23.6 \mathrm{mg}) / \mathrm{kg}$ p.o.) to rats. Full reversibility of MAO-B inhibition was confirmed directly by dialysis experiments. ${ }^{5}$ Ro $19-6327$, which per se did not affect mean arterial blood pressure (MAP), did not potentiate, even at high doses, the tyramine-induced increase in MAP in freely moving rats. ${ }^{5}$ In black mouse striatal tissue, Ro 19-6327 prevented MPTP-induced depletion of brain DA and the formation of the quaternary derivative MPP+5. Ro 19-6327, due to its highly selective inhibitory effect on MAO-B, is an excellent tool to clinically assess whether complete and selective MAO-B inhibition protects dopaminergic neurones from 
age-associated degeneration, possibly by reducing the formation of free radicals or the conversion of MPTP-like compounds into neurotoxins in the CNS. ${ }^{1}$ In contrast to selegiline, Ro 19-6327, even at extremely high doses $(350 \mathrm{mg})$, does not potentiate at all the tyramine pressor effect in healthy subjects. Moreover, this highly selective MAO-B inhibitor, due to its chemical structure cannot be converted into amphetamine-like metabolites. ${ }^{1}$ In healthy subjects, Ro 19-6327 at relatively low doses (40 mg), completely inhibited platelet MAO-B activity for about $12 \mathrm{~h}$; the compound was well tolerated even at the high dose of 350 $\mathrm{mg}$. By positron emission tomography in man it has been shown that 50 mg Ro 19-6327 markedly (> 90\%) inhibited brain MAO$\mathrm{B}$ for at least $12 \mathrm{~h}$. Interestingly, this study showed that the timecourse of platelet MAO-B inhibition virtually paralleled the inhibitory effect of Ro 19-6327 on the brain enzyme. ${ }^{21}$ In conclusion, the highly selective, specific and non-toxic MAO-B inhibitor Ro 19-6327 provides a novel and safe tool to investigate the physiopathological role played by MAO-B in PD and $\mathrm{AD}$ and the consequences of its inhibition in the prevention and/or in the therapy of these diseases.

\section{REFERENCES}

1. Da Prada M, Zürcher G, Kettler R, et al. New therapeutic strategies in Parkinson's disease: inhibition of MAO-B by Ro 19-6327 and of COMT by Ro 40-7592. Adv Behav Biol 1991; 39: 723-732.

2. Glover V, Sandler M, Owen F, et al. Dopamine is a monoamine oxidase B substrate in man. Nature $1977 ; 265: 80-81$.

3. Birkmayer W, Riederer P, Youdim $\mathrm{MBH}$, et al. Potentiation of antikinetic effect after L-dopa treatment by an inhibitor of MAOB, L-deprenyl J Neural Transm 1975; 36: 303-323.

4. Heikkila RE, Manzino L, Cabbat FS, et al. Protection against the dopaminergic neurotoxicity of 1-methyl-4-phenyl-1, 2, 5, 6tetrahydropyridine by monoamine oxidase inhibitors. Nature 1984; 311: 467-469.

5. Haefely WE, Kettler R, Keller HH, et al. Ro 19-6327, a reversible and highly selective monoamine oxidase $B$ inhibitor: a novel tool to explore the MAO-B function in humans. Adv Neurol 1990; 53: 505-512.
6. Tanner CM, Langston JW. Do environmental toxins cause Parkinson's disease? A critical review. Neurology 1980; 40 (Suppl 3): 17-30.

7. Birkmayer W, Knoll J, Riederer P, et al. Increased life expectancy resulting from addition of L-deprenyl to Madopar treatment in Parkinson's disease: a long-term study. J Neural Transm 1985; 64: 113-127.

8. Langston JW. Selegiline as neuroprotective therapy in Parkinson's disease: concepts and controversies. Neurology 1980; 40 (Suppl 3): 61-66.

9. Tariot PN, Cohen RM, Sunderlant T, et al. L-deprenyl in Alzheimer's disease. Arch Gen Psychiatry 1987; 44: 427-433.

10. Piccinin GL, Finali G, Piccinilli M. Neuropsychological effects of L-deprenyl in Alzheimer's type dementia. Clin Neuropharmacol 1990; 13: 147-163.

11. Olanov CW. Oxidation reactions in Parkinson's disease. Neurology 1990; 40 (Suppl 3): 32-39.

12. Youdim MBH. Iron in the brain: implications for Parkinson's and Alzheimer's diseases. Mt Sinai J Med (NY) 1988; 55: 97-101.

13. Da Prada M, Keller HH, Pieri L, et al. The pharmacology of Parkinson's disease: basic aspects and recent advances. Experientia 1984; 40: 1165-1172.

14. Koller WC, Hubble JP. Levodopa therapy in Parkinson's disease. Neurology 1990; 40 (Suppl 3): 40-47.

15. Cedarbaum JM. Clinical pharmacokinetics of antiparkinsonian drugs. Clin Pharmacokin 1987; 13: 141-178.

16. <Madopar> HBS. Europ Neurol 1987; 27 (Suppl 1): 1-138.

17. Lees AJ. Madopar HBS (hydrodynamically balanced system) in the treatment of Parkinson's disease. Adv Neurol 1990; 53: 475-482.

18. Zürcher G, Keller HH, Kettler R, et al. Ro 40-7592, a novel, very potent and orally active inhibitor of catechol-O-methyltransferase: a pharmacological study in rats. Adv Neurol 1990; 53: 497-503.

19. Koller WC, Giron LT. Selegiline $\mathrm{HCl}$ : selective MAO-type B inhibitor. Neurology 1990; 40 (Suppl 3): 58-60.

20. Reynolds GP, Elsworth JP, Blank K, et al. Deprenyl is metabolized to methamphetamine and amphetamine in man. Brit $\mathrm{J}$ Clin Pharmacol 1978; 6: 542-544.

21. Price GW, Bench CJ, Cremer JC, et al. Inhibition of human brain monoamine oxidase B by Ro 19-6327 - in vivo measurement using positron emission tomography. Eur J Pharmacol 1990; 183: 166. 